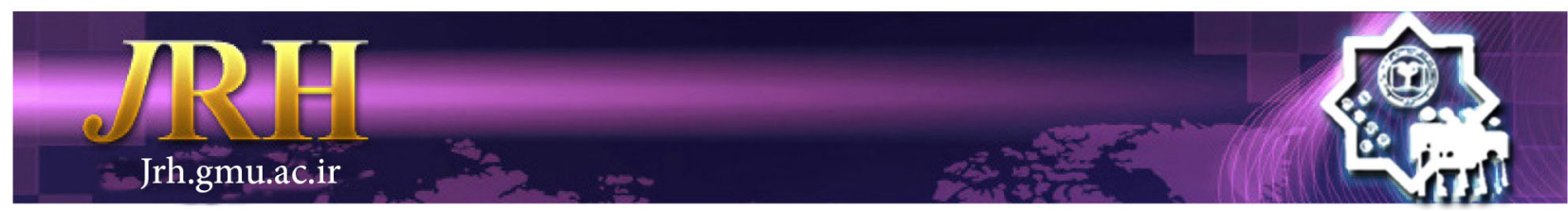

\title{
The effect of regular aerobic training on beta cell function and serum insulin in sedentary male's smoker
}

Daniel Tarmast ${ }^{1}$, Mojtaba Eizadi ${ }^{2}$, Mojtaba Ghasemi Shob ${ }^{3}$, Ashraf Amini $^{4}$

\author{
Journal of Research \& Health \\ Social Development \& Health Promotion \\ Research Center \\ Vol. 8, No.5, Sep \& Oct 2018 \\ Pages: $451-458$ \\ DOI: 10.29252 jjh. 8.5 .451 \\ Original Article
}

1. Department of Physical Education and Sport Sciences, Faculty of Humanities, Parand Branch, Islamic Azad University, Parand, Iran

2. Correspondence to: Department of Exercise Physiology, Faculty of Humanities, Saveh Branch, Islamic Azad University, Saveh, Iran

E-mail: izadimojtaba2006@yahoo.com

3. Department of Physical Education and Sport Sciences, Khatam ol-Anbia (PBU) University, Tehran, Iran

4. Department of Physical Education and Sport Sciences, Amirkabir University of Technology, Tehran, Iran

Received: 8 Jan 2018

Accepted: 20 Apr 2018

How to cite this article: Tarmast D, Eizadi M, Ghasemi Shob M, Amini A. The effect of regular aerobic training on beta cell function and serum insulin in sedentary male's smoker. $J$ Research \& Health2018; 8(5): 451- 458.

\begin{abstract}
Previous studies have shown that nicotine can affect beta cell function and insulin secretion in cigarette smokers. The aim of present study was to evaluate the effect of 10 weeks aerobic exercise on insulin and beta cell function in smokers. In this semiexperimental study with pre and post-training design, a total of 36 adult smoker men aged $41 \pm 2.5$ years were selected into either exercise $(\mathrm{n}=18)$ or control $(\mathrm{n}=18)$ groups. Exercise participants underwent a 10-weeks supervised aerobic training intervention (3 days/weeks for 45-60 min at 60-80\% HR max). Pre (baseline) and post training of fasting glucose, insulin serum and beta cell function were measured of two groups. Aerobic intervention resulted in significant decrease in fasting glucose. In addition, aerobic training induced a significant increase beta cell function and serum insulin in exercise group. The control group exhibited no significant change in any variables. Long term aerobic training is associated with improvement in glycemic profile in male's smoker. The benefits effect of aerobic intervention on glucose homeostasis in cigarette smokers may be attributed to improved beta cell function.
\end{abstract}

Keywords: Exercise, Insulin, Pancreas, Smoking

\section{Introduction}

Smoking is rapidly increasing worldwide and is considered as one of the most effective markers in the prevalence of chronic diseases such as atherosclerosis, respiratory and cardiovascular diseases, and other chronic diseases [1-3], as chronic diseases such as asthma and diabetes are the long-term consequences of it. It has been shown that smoking due to multiple systems leads to an increase in $\operatorname{IgE}$ and the spread of atopic and asthmatic diseases, which is associated with hyperactivity of macrophages and dendritic cells [4].

On the other hand, although scientific sources have introduced several factors affecting the prevalence of type II diabetes, such as increased fat intake, inactivity and decreased physical activity, obesity, and inheritance [5], recent studies have also strongly supported the rise in the prevalence of type II diabetes in smokers and even those who are exposed to smoke [6]. Smoking can lead to decreased insulin sensitivity in diabetic patients or non-diabetic individuals [7]. Compared to non-smokers, the body of smokers is less sensitive to insulin, and it is interesting that $r$ a few weeks or months after quitting it, this sensitivity returns. Cigarette smoking is also associated with central obesity which is main factor contributing to increased insulin resistance [8]. Apart from the effect on insulin function 
in target tissues, new studies have also revealed beta-cell damage in response to smoking [9]. On the other hand, the decrease in the synthesis and release of insulin from pancreas beta cells leads to lower systemic insulin levels in smokers than non-smokers, which in turn leads to an increase in glucose and glycosylated hemoglobin [10].

Hence, it seems that developing appropriate strategies aimed at increasing insulin release from the pancreas is associated with the reduction of glucose levels in smokers. In this regard, although no studies have ever been conducted directly on smokers, some studies have reported the increase in beta cell function and serum insulin levels in response to exercise training in non-smoker populations. In the study of Eizadi et al. for example, 3 months of aerobic training led to a significant increase in betacell function along with decreased circulating glucose levels in type II diabetic men [11]. It has been also speculated that regular exercise training not only by decrease insulin resistance but also by increased mass and beta cell function can be improve glucose homeostasis [12]. In study by Bolem et al. beta cell function increase by 7 aerobic exercise sessions in elderly males with impaired glucose tolerance [13]. However, in a study by Maltai et al. 4 months resistance training did not lead to changes in glucose and insulin levels in overweight elderly men [14]. Some other studies have also supported the increased beta cell function and insulin levels in response to various exercise methods such as aerobic or resistance exercises in overweight people [15]. Based on these conflict reports in other populations and no study that directly examined the effect of aerobic training on the pancreas beta cells, fasting glucose, and insulin levels in smokers, this study set to determine the impact of 10 weeks of aerobic training on the performance index of beta cells and glucose in inactive male smokers.

\section{Method}

In this semi-experimental study with pre and post-training design, thirty six inactive adult smoker men matched according to age and weight were selected first through purposeful sampling and then divided into exercise (aerobic training, 10-weeks, 3d/wk $\mathrm{n}=18)$ and control $(\mathrm{n}=18)$ group based on random allocation using a Table of random numbers. (Parand, Iran, Fall). The protocol was conducted with the approval the ethics committee of Islamic Azad University, Iran. Sample size was decided determined to Equation 1.

$$
n=\frac{\left(\sigma_{1}^{2}+\sigma_{1}^{2}\right)\left(Z_{1-\frac{\beta}{2}}+Z_{1-\beta}\right)^{2}}{d^{2}}
$$

Prior the interventions, the purpose of study were detailed and all participants freely read and informed consent. The main inclusion criteria for participate was cigarette smoking at least for 3 years. All participants were non-alcoholic and inactive (they had not been involved in regular physical activity in the previous 6 months). None of the participants had a history of injury that would prevent exercise. Those with history of chronic diseases (asthma, metabolic syndrome, diabetes, cardiovascular or other diseases) were also excluded from the study.

Weight and height were measured by same person to the nearest $0.1 \mathrm{~kg}$ and the nearest 0.1 $\mathrm{cm}$, respectively. The BMI was calculated for each individual as the weight (in kilograms) divided by the height (in square meters). Abdominal circumference was measured in the most condensed part using a non-elastic cloth meter. Visceral fat and body fat (\%) was determined using body composition monitor (OMRON- BF 508, Finland). Each of these measurements was conducted three times and the average was reported.

Study design illustrated consisted of running exercise training thrice weekly at $60-80 \%$ HRmax lasted for 10-week (11, Modified). The running protocol had been done by participants after warmed-up (5-10 min). To prevent high stress and perform overload principle, exercise sessions volume was progressively increased from 15 to 45 minutes and exercise intensity was gradually increased from 60 to 80 (\%) HRmax. To completely accurate the exercise training protocol effects, participants were 
asked to do not take part in other exercise training.

Pre and post training of fasting blood samples were obtained to measure biochemical variables of 2 groups. So that, blood samples were obtained following a 12-hour overnight fast (8:00-9:00 a.m.) before and $48 \mathrm{~h}$ after lasted exercise session with regard to measure serum insulin and glucose of all participants. All participants were asked to avoid doing any serious physical activity for 48-h before blood sampling. Blood samples were dispensed into EDTA-coated tubes and centrifuged for separate serum and aliquots stored at $-80{ }^{\circ} \mathrm{C}$ until biochemical analyses were performed. Glucose concentration was determined by the glucose-oxidase method (Pars Azmoon, Tehran). Insulin was determined by ELISA method (Demeditec, Germany) and the intra- assay and inter-assay coefficient of variation of the method were $2.6 \%$ and 2.88 respectively. Beta cell function was calculated using fasting insulin and glucose levels [16].

Data analysis: SPSS-16 (SPSS, Chicago, IL, USA) used for statistical analyses of all variables. Kolmogorov-Smirnov normality test used to analyze normal distribution of the data, subsequent analysis was independent and paired sample t test. Independent sample T-test was used to compare all variables between two groups at baseline. Paired sample t test was used to determine the mean differences between pre and post-training values of each variable. A p-value $<0.05$ was considered significant.

\section{Results}

Based on independents $\mathrm{T}$ test, there were no statistically significant differences between the exercise and control participants with regard to anthropometrical and clinical characteristics at baseline $(\mathrm{p}>0.05$, Table 1$)$.

Table 1 Mean and standard deviation of anthropometrical and clinical characteristics at pre and post training in studied groups

\begin{tabular}{lccc}
\hline Variables & Exercise group & Control group & Sig \\
\hline Age & $40.7 \pm 2.41$ & $41.3 \pm 2.56$ & 0.782 \\
Weight $(\mathrm{kg})$ & $93.68 \pm 4.04$ & $94.01 \pm 3.59$ & 0.542 \\
$\mathrm{AC}(\mathrm{cm})$ & $101.4 \pm 6.1$ & $101.5 \pm 6.13$ & 0.635 \\
Body fat $(\%)$ & $30.6 \pm 1.23$ & $30.57 \pm 1.25$ & 0.523 \\
BMI $\left(\mathrm{kg} / \mathrm{m}^{2}\right)$ & $30.7 \pm 1.26$ & $30.68 \pm 1.15$ & 0.363 \\
Visceral fat & $12.3 \pm 1.29$ & $12.5 \pm 1.68$ & 0.549 \\
Glucose $(\mathrm{mg} / \mathrm{dl})$ & $124 \pm 34$ & $122 \pm 33$ & 0.853 \\
Insulin $(\mu \mathrm{IU} / \mathrm{ml})$ & $6.03 \pm 1.11$ & $6.09 \pm 2.01$ & 0.469 \\
Beta cell function & $42.07 \pm 5.94$ & $44.4 \pm 7.92$ & 0.645 \\
(BF-HOMA) & & & \\
\hline
\end{tabular}

;AC: abdominal circumference; BF: body fat percentage

BMI: body mass index

Anthropometric characteristics of the study participants, before and after aerobic intervention are described in Table 2 . Compared to pre training, exercise group obtained significant decreases in body weight, visceral fat $(\mathrm{p}<0.001)$, body fat percentage $(p<0.001)$ and the other anthropometrical indexes in exercise group $(\mathrm{p}<0.05)$ but these variables remained without changed in control participants $(\mathrm{p}>0.05)$ (Table 2).

Table 2 Mean and standard deviation of anthropometrical characteristics at pre and post training in studied groups

\begin{tabular}{lcccccc}
\hline Variables & Pre-training & $\begin{array}{c}\text { Exercise group } \\
\text { post-training }\end{array}$ & Sig & Pre-train & $\begin{array}{c}\text { Control group } \\
\text { post-training }\end{array}$ & Sig \\
\hline Weight (kg) & $93.68 \pm 4.04$ & $91.95 \pm 4.32$ & $<0.001$ & $94.01 \pm 3.59$ & $94.2 \pm 3.31$ & 0.264 \\
AC (cm) & $101.4 \pm 6.1$ & $99.3 \pm 5.9$ & 0.001 & $101.5 \pm 6.13$ & $101.8 \pm 5.86$ & 0.430 \\
Body fat (\%) & $30.6 \pm 1.23$ & $29.6 \pm 1.48$ & $<0.001$ & $30.57 \pm 1.25$ & $30.5 \pm 1.18$ & 0.847 \\
BMI (kg/m2) & $30.7 \pm 1.26$ & $30.1 \pm 1.31$ & $<0.001$ & $30.68 \pm 1.15$ & $30.7 \pm 1.09$ & 0.260 \\
Visceral fat & $12.3 \pm 1.29$ & $10.3 \pm 2.68$ & 0.21 & $12.5 \pm 1.68$ & $12.3 \pm 2.41$ & 0.459 \\
\hline
\end{tabular}

AC, abdominal circumference; $\mathbf{B F}$, body fat percentage; BMI, body mass index 
Based on what is noted, this study aimed to determine whether beta cell function, insulin and fasting glucose was altered with an aerobic training intervention in cigarette smokers. Table 3 presents the pre and post training circulating levels of serum insulin, glucose and beta cell function of two groups.

The difference between pre and post training for each variable (delta) were measured, and then compare them between the two groups with the Independent $\mathrm{T}$ test. Data showed significant difference between 2 groups with regard to delta of beta cell function $(\mathrm{p}=0.025)$, insulin $(\mathrm{p}=0.037)$ and glucose $(\mathrm{p}=0.001)$.
In the following, paired sample $\mathrm{T}$ test was used to determine intra-group differences for each variable. Based on data, aerobic training induced significant increase in beta cell function compared with pre-training in the exercise group $(\mathrm{p}=0.021)$ but this variable remained unchanged in the control participants $(\mathrm{p}=0.441$, Figure 1$)$. We observed a significant increase for serum insulin by aerobic training in exercise group $(p=0.041$, Figure 2) but not in control group $(\mathrm{p}=0.614)$. Compared to pre-training, glucose concentration decreased significantly $(\mathrm{p}=0.005$, Figure 3 ) after aerobic intervention but was not changed in control participants $(\mathrm{p}=0.453)$.

Table 3 Circulation level of clinical characteristics at pre and post training in studied groups (Mean $\pm S D)$.

\begin{tabular}{lcccccc}
\hline Variable & Pre-training & $\begin{array}{c}\text { Exercise group } \\
\text { post-training }\end{array}$ & Sig & Pre-training & $\begin{array}{c}\text { Control group } \\
\text { post-training }\end{array}$ & Sig \\
\hline Glucose $(\mathrm{mg} / \mathrm{dl})$ & $34 \pm 124$ & $32 \pm 106$ & 0.005 & $33 \pm 122$ & $25 \pm 120$ & 0.453 \\
Insulin $(\mu \mathrm{IU} / \mathrm{ml})$ & $1.11 \pm 6.03$ & $2.36 \pm 7.48$ & 0.041 & $2.01 \pm 6.09$ & $1.68 \pm 6.29$ & 0.622 \\
$\begin{array}{l}\text { Beta cell function } \\
\text { (BF-HOMA) }\end{array}$ & $5.94 \pm 42.07$ & $8.63 \pm 67.5$ & 0.021 & $7.92 \pm 44.4$ & $9.81 \pm 46.9$ & 0.621 \\
\hline
\end{tabular}

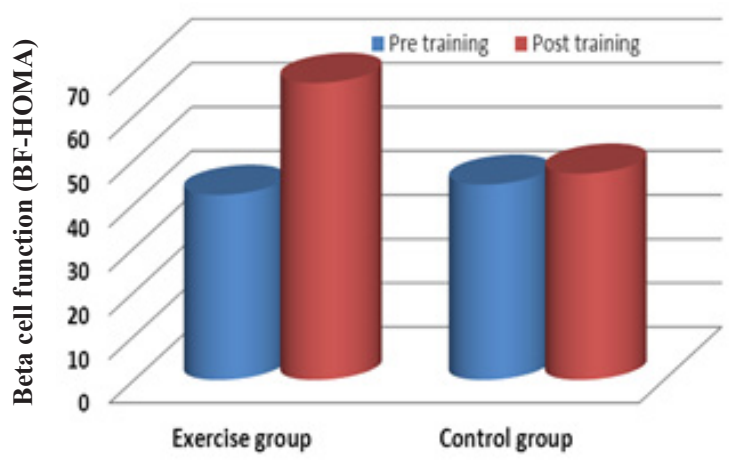

Figure 1 Pre and post training of beta cell function in studied groups. Aerobic training resulted in significant increase in beta cell function in exercise group

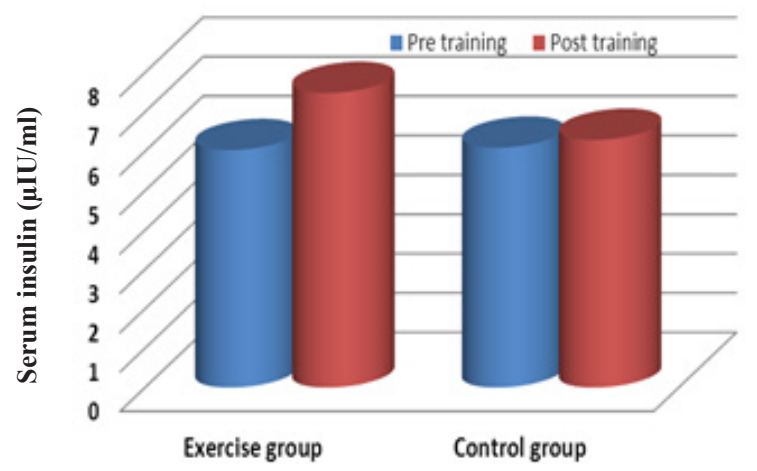

Figure 1 Pre and post training of serum insulin in studied groups. Aerobic training resulted in significant increase in serum insulin in exercise group

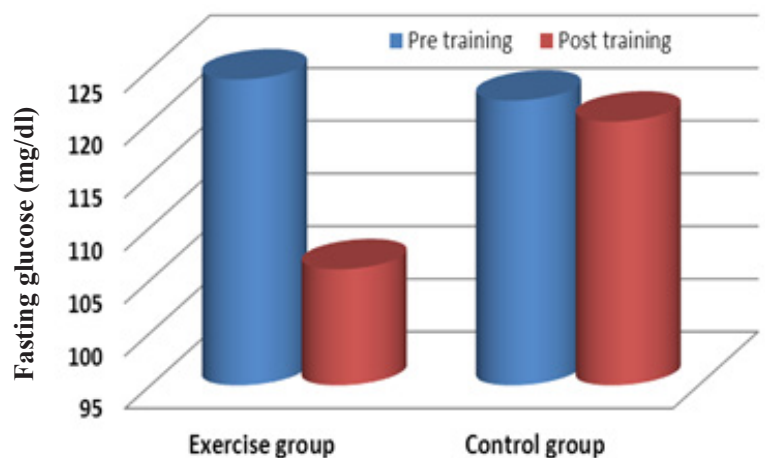

Figure 1 Pre and post training of fasting glucose in studied groups. Aerobic training resulted in significant decrease in fasting glucose in exercise group

\section{Discussion}

An increase in the function of beta cells in response to aerobic intervention is the main 
result of the current study. In other words, 10 weeks of aerobic exercise, three sessions per week, led to a significant increase in beta cell function in smokers who had previously had an inactive lifestyle. On the other hand, reduction of fasting glucose levels and increased serum insulin are other outcomes. These findings are reported while none of the so-called variables in the control subjects, who did not participate in the exercise program, showed any meaningful changes. In this regard, although no research has been reported on smokers, some studies have supported the beneficial effects of exercise trainings on blood glucose levels, insulin sensitivity, and beta cell function in healthy or patient non-smoker populations.

For instance, in the study by Solomon et al., 12 weeks of aerobic training led to a significant decrease in fasting glucose and glycosylated hemoglobin and $90 \%$ increase in insulin sensitivity in type II diabetic patients [17]. These researchers also introduced improvements in the beta cell function in response to aerobic intervention as a key indicator of improving glycemic control. Malin et al. suggested an improvement in beta cell function in prediabetic individuals with low insulin secretion requires exercise trainings with long-term periods [18]. In contrast, Marquis et al. suggested that 9 months of periodic and resistance training combined with the Mediterranean diet did not lead to a change in the function of beta cells and glycosylated hemoglobin in middle-aged obese participants [19].

In line with the present findings, other studies have also reported the role of different training practices, such as running on treadmill and swimming in maintaining the mass and function of beta cell $[14,20]$. Scientific sources state that exercise training increases beta cell mass by hyperplasia, and hyperplasia results from increased beta cell proliferation and decreased apoptosis [21]. Solomon et al. also attributed improvements in glycemic profile and beta cell function following a 12-week aerobic training in patients with type II diabetic to $66 \%$ reduction in first-phase insulin secretion and $46 \%$ reduction in second-phase insulin secretion [17]. Despite the evidence that supports the increase in the function of beta cells in smokers, the findings of a recent study showed that stopping cigarette smoking for 3 months would improve both insulin resistance index and beta cell function in male and female smokers [22].

A study on American populations revealed the prevalence of hyperinsulinemia in smokers compared with non-smokers [23]. It should be noted that the researchers found that hyperinsulinaemia in smokers was limited to fasting insulin levels, not other times of the day [24]. On the other hand, the increase in nicotine from cigarette leads to the destruction and death of beta cells. It has been shown that nicotine affects beta cells directly or indirectly through the parasympathetic ganglia [22]. Studies on animal and in vitro experiments have also indicated that exposure to nicotine leads to destruction and loss of beta cells $[25,26]$. In rabbits, increasing nicotine concentration inhibits glucose-induced insulin secretion, while low nicotine levels stimulate insulin release from pancreas beta cells [27]. The findings of Bhattacharjee revealed that 21-day supplementation of vitamin $B_{12}$ and folic acid in Wistar rats led to the reduction of oxidative stress in cells as an important step in improving nicotinic cell damage, and it also improved the function of cells in the rats' pancreas and inhibited the secretion of pre-inflammatory mediators [9]. It was noted that folic acid and vitamin B12 supplementation improves the function of beta cells by inhibiting nicotinic degradation factors in beta cells and reducing the production of free radicals, TNF- $\alpha$ and IL-6 and changing oxidative stress conditions and reducing cell death.

Although some studies have indicated that the decrease in the function of beta cells has a strong correlation with the reduction of expression of GLUT2 [28], increasing the function of beta cells may also be attributed to hormonal changes in response to aerobic exercises since some scientific sources have pointed to the influential role of some hormones, especially inflammatory or anti-inflammatory cytokines in the synthesis or release of insulin, or, in 
other words, the function of beta cells [29]. In this regard, certain studies have reported improvements in cytokines associated with insulin function such as adiponectin, resistin, leptin and other cytokines in response to short or long-term exercise training [30,31].

On the other hand, the disorder of the systemic levels of these hormones in the presence of smoking has been reported many times; for example, reduction of adiponectin concentration in cigarettes has also been demonstrated [30]. On the other hand, a direct and significant correlation has been reported between hypoadiponectinemia and decreased beta cell function [32,33]. Accordingly, it is likely that the decrease in the function of beta cells in smokers has some roots in hypoadiponectinemia. In a study on Chinese, adiponectin was referred to as a predictor index of beta cell function [34]. Hence, the increase in beta cell function in this study may be attributed to hormonal changes or changes in their receptors in response to exercise trainings. Twelve weeks of aerobic exercise in the two recent studies led to a significant increase in both serum adiponectin and beta cell function in patients with type II diabetic $[11,35]$. In contrast, reduction of blood glucose levels or increase of insulin secretion and beta cell function in the present study can be attributed to weight loss or decrease in abdominal obesity due to aerobic trainings. It should be noted that the smoker men in this study were actually obese (abdominal obesity), and aerobic trainings were associated with a significant decrease in weight, body fat (\%), and abdominal obesity. Malin et al. reported that 12 weeks of aerobic training at $85(\%)$ HRmax rate led to a significant increase in beta-cell function in prediabetic obese individuals [18]. Eizadi et al. also stated that 12 weeks of aerobic training led to an increase in beta-cell function and a decrease in circulating glucose along with a decrease in body fat and abdominal obesity in middle-aged obese men [36]. These researchers concluded that long-term exercise trainings lead to a reduction in hyperglycemia in healthy or patient obese individuals by improving the inflammatory components affective on beta- cell function and insulin resistance in obese individuals.

\section{Conclusion}

The relatively long-term aerobic training leads to the increased beta-cell function along with glycemic control in smokers. The improvement in the function of beta cells in response to aerobic intervention has been achieved in the presence of continued smoking. Based on the available evidence, it seems that regular aerobic exercises result in an increase in the function of beta cells and decrease in blood glucose levels through the inhibition of the adverse effects of nicotine on beta cells in the pancreas, as well as the increase in the mass and number of these cells.

\section{Acknowledgments}

We are particularly grateful to all participants who participated in the study. We thank the Research Deputy of Islamic Azad University for their financial support and cooperation in implementing this project.

\section{Contribution}

Study Design: ME, TD

Data collection and analysis: MGhSh, AA

Manuscript preparation: ME, TD

\section{Conflict of Interest}

No conflict of interest are declared by the author(s).

\section{Funding}

The authors received no financial support for the research, authorship and/or publication of this article.

\section{References}

1- Wang CN, Yang GH, Wang ZQ, et al. Role of perivascular adipose tissue in nicotine induced endothelial cell inflammatory responses. Mol Med Rep2016; 14(6): 5713-8.

2- Fan LH, He Y, Xu W, et al. Adiponectin may be a biomarker of early atherosclerosis of smokers and decreased by nicotine through KATP channel in adipocytes. Nutrition2015; 31(7-8): 955-8.

3- Mao J, Liu J, Pang X, et al. Nicotine induces the 
expression of C-reactive protein via MAPK-dependent signal pathway in U937 macrophages. Mol Cells2012; 34(5): 457-61.

4- Arnson Y, Shoenfeld Y, Amital H. Effects of tobacco smoke on immunity, inflammation and autoimmunity. $J$ Autoimmun2010; 34(3): 258-65.

5- Hong JW, Ku CR, Noh JH, Ko KS, Rhee BD, Kim DJ. Association between self-reported smoking and hemoglobin A1c in a korean population without diabetes: the 2011-2012 korean national health and nutrition examination survey. PLoS One2015; 10(5): e0126746.

6- Hsu CC, Hwang SJ, Tai TY, et al. Cigarette smoking and proteinuria in Taiwanese men with Type 2 diabetes mellitus. Diabet Med2010; 27(3): 295-302.

7- Nakanishi N, Nakamura K, Matsuo Y, Suzuki K, Tatara

$\mathrm{K}$. Cigarette smoking and risk for impaired fasting glucose and type 2 diabetes in middle-aged Japanese men. Ann Intern Med2000; 133(3):183-91.

8- Weitzman M, Cook S, Auinger P, et al. Tobacco smoke exposure is associated with the metabolic syndrome in adolescents. Circulation2005; 112(6): 862-9.

9- Bhattacharjee A, Prasad SK, Pal S, et al. Possible involvement of iNOS and TNF- $\alpha$ in nutritional intervention against nicotine-induced pancreatic islet cell damage. Biomed Pharmacother2016; 84: 1727-38.

10- Nishida Y, Hara M, Sakamoto T, et al. Japan multiinstitutional collaborative cohort (J-MICC) study group. Influence of cigarette smoking and inflammatory gene polymorphisms on glycated hemoglobin in the Japanese general population. Prev Med Rep2016; 3: 288-95.

11- Eizadi M, Behboudi 1, Zahedmanesh F, Afsharmand $Z$. Effect of acute and chronic exercise on beta-cell function in diabetic patients. Knowledge \& Health2012; 6(4): 15-9.

12- Park S, Hong SM, Lee JE, Sung SR. Exercise improves glucose homeostasis that has been impaired by a high-fat diet by potentiating pancreatic $\beta$-cell function and mass through IRS2 in diabetic rats. $J$ Appl Physiol2007; 103(5): 1764-71.

13- Bloem CJ, Chang AM. Short-term exercise improves B- cell function and insulin resistance in older people with impaired glucose tolerance. J Clin Endocrinol Metab2008; 93(2): 387-92.

14- Maltais ML, Perreault K, Courchesne-Loyer A, Lagacé JC, Barsalani R, Dionne IJ. Effect of resistance training and various sources of protein supplementation on body fat mass and metabolic profile in sarcopenic overweight older adult men: a pilot study. Int J Sport Nutr Exerc Metab2016; 26(1): 71-7.

15- Abou Assi H, Slentz CA, Mikus CR, et al. The effects of aerobic, resistance, and combination training on insulin sensitivity and secretion in overweight adults from STRRIDE AT/RT: a randomized trial. J Appl Physiol2015; 118(12): 1474-82.
16- Oxford Centre for Diabetes, Endocrinology and Metabolism. Diabetes Trial Unit. HOMA Calculator. Available from: http://www.dtu.ox.ac.uk/ Acessed March 2009.

17- Solomon TP, Malin SK, Karstoft K, Kashyap SR, Haus JM, Kirwan JP. Pancreatic $\beta$ eta-cell function is a stronger predictor of changes in glycemic control after an aerobic exercise intervention than insulin sensitivity. J Clin Endocrinol Metab2013; 98(10): 4176-86.

18- Malin SK, Solomon TP, Blaszczak A, Finnegan S, Filion J, Kirwan JP. Pancreatic ßeta-cell function increases in a linear dose-response manner following exercise training in adults with prediabetes. Am J Physiol Endocrinol Metab2013; 305(10): 1248-54.

19- Marquis-Gravel G, Hayami D, Juneau M, et al. Intensive lifestyle intervention including high-intensity interval training program improves insulin resistance and fasting plasma glucose in obese patients. Prev Med Rep2015; 2: 314-8.

20- Pold R, Jensen LS, Jessen N, et al. Long-term AICAR administration and exercise prevents diabetes in ZDF rats. Diabetes2005; 54(4): 928-34.

21- Park S, Hong SM, Lee JE, Sung SR. Exercise improves glucose homeostasis that has been impaired by a high-fat diet by potentiating pancreatic B- cell function and mass through IRS2 in diabetic rats. $J$ Appl Physiol2007; 103(5): 1764-71.

22- Stadler M, Tomann L, Storka A, et al. Effects of smoking cessation on $\beta$-cell function, insulin sensitivity, body weight, and appetite. Eur J Endocrinol2014; 170(2): 219-7.

23- Facchini FS, Hollenbeck CB, Jeppesen J, Chen YD, Reaven GM. Insulin resistance and cigarette smoking. Lancet 1992; 339(8802): 1128-30.

24- Ronnemaa T, Ronnemaa EM, Puukka P, Pyorala K Laakso M. Smoking is independently associated with high plasma insulin levels in nondiabetic men. Diabetes Care1996(19): 1229-32.

25- Bruin JE, Gerstein HC, Morrison KM, Holloway AC. Increased pancreatic $\beta$ eta-cell apoptosis following fetal and neonatal exposure to nicotine is mediated via the mitochondria. Toxicol Sci2008; 103(2): 362-70.

26- Woynillowicz AK, Raha S, Nicholson CJ, Holloway AC. The effect of smoking cessation pharmacotherapies on pancreatic $b$ cell function. Toxicol. Appl. Pharmacol2012; 265(1): 122-7.

27- Tjalve H, Popov D. Effect of nicotine and nicotine metabolites on insulin secretion from rabbit pancreas pieces. Endocrinology1973; 92(5): 1343-8.

28- Tanaka Y, Gleason CE, Tran PO, Harmon JS, Robertson RP. Prevention of glucose toxicity in HIT-T15 cells and Zucker diabetic fatty rats by antioxidants. Proc Natl Acad Sci USA1999; 96(19): 10857-62. 
29- Tang Z, Yuan L, Gu C, Liu Y, Zhu L. Effect of exercise on the expression of adiponectin mRNA and GLUT4 mRNA in type 2 diabetic rats. J Huazhong Univ Sci Technolog Med Sci2005; 25(2): 191-3, 201.

30- de Salles BF, Simão R, Fleck SJ, Dias I, KraemerAguiar LG, Bouskela E. Effects of resistance training on cytokines. Int J Sports Med2010; 31(7): 441-50.

31- Kumada M, Kihara S, Sumitsuji S, et al. Association of hypoadiponectinemia with coronary artery disease in men. Arterioscler Thromb Vasc Biol2003; 23(1): 85-9.

32- Wang C, Guan Y, Yang J. Cytokines in the progression of pancreatic Beta-Cell dysfunction. Int J Endocrinol2010; 515136.

33- Xiang AH, Kawakubo M, Trigo E, Kjos SL, Buchanan TA. Declining Beta-cell compensation for insulin resistance in Hispanic women with recent gestational diabetes mellitus: association with changes in weight, adiponectin, and C-reactive protein. Diabetes Care2010; 33(2): 396-401.

34- So WY, Tong PC, Ko GT. Low plasma adiponectin level, white blood cell count and Helicobacter pylori titre independently predict abnormal pancreatic $\beta$ eta-cell function. Diabetes Res Clin Pract2009; 86(2): 89-95.

35- Parsian H, Eizadi M, Khorshidi D, Khanali F. The effect of long-term aerobic exercise on serum adiponectin and insulin sensitivity in type 2 diabetic patients. Journal of Jahrom University of Medical Sciences2013; 11(1): 36-43.

36- Eizadi M, Sokhanguei Y, Eghdami A, Banaeifar A. Effect of aerobic exercise on Pancreas $\beta$ eta-cell function in adult obese males. Journal of Birjand University of Medical Sciences2014; 21(2): 203-10.

Copyright $(2016$ ASP Ins. This open-access article is published under the terms of the Creative Commons Attribution-NonCommercial 4.0 International License which permits Share (copy and redistribute the material in any medium or format) and Adapt (remix, transform, and build upon the material) under the Attribution-NonCommercial terms. 